\title{
Pecan Cultivar Susceptibility to Sooty Mold Related to Leaf Surface Morphology
}

\author{
Darrell Sparks \\ Department of Horticulture, University of Georgia, Athens, GA 30602
}

I.E. Yates

Agricultural Research Service, U.S. Department of Agriculture, Russell Research Center, P. O. Box 5677 Athens, GA 30613

Additional index words. Carya illinoensis, Polychaeton, breeding, alternate bearing, electron microscopy

\begin{abstract}
Sooty mold washed from leaves of four cultivars of pecan [Carya illinoensis (Wangenh.) C. Koch] was quantified. The amounts of sooty mold accumulation differed significantly $(P \leq 0.05)$ among the cultivars. Leaf surface morphology of each cultivar was examined. A higher incidence of sooty mold was associated with cultivars having a rough, granulated leaf topography than those with smoother leaf surfaces. Characteristics of leaf surface morphology may be useful in selecting germplasms with reduced susceptibility to sooty mold accumulation.
\end{abstract}

A consequence of the feeding activity of a population of aphids [Monella caryella (Fitch) and Monelliopsis pecanis Bissell] in pecan orchards may be an accumulation of a fungal mat on the adaxial leaf surface. As the aphids feed on the leaf, they excrete a viscous substance called honeydew (Tedders and Smith, 1976). The honeydew is rich in plant-derived carbohydrates (Tedders et al., 1982) that provide a medium for the growth of the fungus. Although the fungal mat resulting from the growth of sooty mold may occur early in the growing season, it is usually most common and intense late in the season, when the fruits are in the stage of rapid kernel development. The energy drain of fruit maturation coupled with an accumulation of sooty mold on the leaves would be expected to have serious deleterious effects on crop productivity. The pecan kernel is high in lipids $(\approx 70 \%)$, with most of the lipid accumulation occurring during $\approx 4$ weeks. If leaf efficiency is substantially reduced during this interval, the kernel does not develop fully and carbohydrate accumulation for next year's growth and fruiting may be suppressed to the point that alternate bearing is induced (Sparks, 1986).

From macroscopic observation, sooty mold growth on aphid excrement does not appear to cause physical lesions on the leaf, as is the case in certain other plant species infected with sooty mold (Parbery and Brown, 1986). The deleterious effect of sooty mold on pecan trees appears to be derived from its shading the leaf, thereby reducing leaf photosynthetic capacity (Tedders and Smith, 1976; Wood et al., 1988). In addition to reduced leaf efficiency, repeated orchard observations indicate that heavy sooty mold accumulation can cause premature leaf abscission. Premature leaf abscission reduces return bloom and subsequent crop productivity (Hinrichs, 1962; Worley, 1979), especially if defoliation occurs during a season of high fruiting stress (Sparks and Brack, 1972).

Field observations indicate that not all cultivars appear equally susceptible to sooty mold accumulation. Although there appear to be relatively small differences among pecan cultivars to aphid

Received for publication 16 Jan. 1990. We gratefully acknowledge the assistance of Don R. Reynolds, Curator of Botany, Natural History Museum, Los Angeles, Calif., for identification of the fungus and its associated fruiting bodies that compose the sooty mold growth on the leaves in this study. Trade names arc used in this publication to provide specific information. Mention of a trade name does not constitute a guarantee or warranty of the product or an endorsement by the USDA over other products not mentioned. The cost of publishing this paper was defrayed in part by the payment of page charges. Under postal regulations, this paper therefore must be hereby marked advertisement solely to indicate this fact. susceptibility, as illustrated for 'Stuart' and 'Schley' (Tedders, 1978), the few reported cases of resistance to attack ['Curtis', 'Moore', and 'Moneymaker' (Moznette et al., 1940)] are not permanent, as they lose their resistance with leaf age (Tedders, 1978). The same is probably the case with 'Pawnee' (Thompson and Yates, 1986), which also initially shows some resistance. At the other extreme, 'Cheyenne' appears to exhibit substantial susceptibility to aphids, but this has not been quantified.

Cultivar-related differences in leaf morphology would be an easily detectable characteristic that could serve as a marker in cultivar breeding programs to select genotypes with reduced susceptibility to sooty mold accumulation. The objective of this study was to determine whether the leaf surface of cultivars with heavy sooty mold accumulation is morphologically different from those not commonly found associated with large amounts of sooty mold.

\section{Materials and Methods}

Source of leaves. Leaves were collected during Fall 1989 from 20-year-old trees of 'Curtis', 'Desirable', 'Stuart', and 'Schley' growing at the Univ. of Georgia Horticulture Farm, Watkinsville. The trees were located within a radius of $122 \mathrm{~m}$ of each other and had been subjected to the same pest management program during the growing season. Consequently, the leaves of all cultivars had been exposed to similar environmental conditions and to presumably equal levels of insect and fungal pressures.

Quantification of sooty mold accumulation. In mid-November, 12 leaves were collected from each of three trees of each cultivar. Leaves were taken from the midpoint of the first cycle shoot growth. The leaf collection was evenly distributed around each tree so that three leaves each were collected from the north, east, south, and west sides of each tree. The terminal leaflet from each leaf was removed and the total weight for all 12 leaflets was determined. The terminal leaflets were then submerged in $0.05 \% \mathrm{NaDodSO}_{4}(\mathrm{SDS})$ and agitated for $5 \mathrm{~min}$ on a wrist-action shaker to facilitate removal of the sooty mold. Leaflets were removed from the SDS and gently rubbed by hand to loosen any tightly adhering sooty mold. The leaflets were then agitated $5 \mathrm{~min}$ more in SDS. After the leaflets were removed from the wash bath, the sooty mold was collected by centrifugation and resuspended in $20 \mathrm{ml}$ of deionized-distilled water to remove residual SDS. The sample was centrifuged again and resuspended in 3 to $4 \mathrm{ml}$ of distilled water. The concentrated sooty mold suspension was placed in a previously 
weighed glass petri dish and dried at $72 \mathrm{C}$ for $24 \mathrm{hr}$ before weighing for quantifying the sooty mold for each sample.

Preparation of leaves for scanning electron microscopy (SEM). Nine leaflets were collected from each cultivar for examination by SEM. The leaflet subtending the terminal leaflet was removed from each of three leaves collected from three trees of each cultivar. Leaflets were gently washed with water to remove extraneous debris from the leaf surface. Leaflet samples of 'Desirable' and 'Stuart' were examined before being washed, and those of 'Stuart' were examined after peeling away the sooty mold.

Scanning electron microscopy. Portions of leaflets selected for examination were located at the midpoint of the leaflet length, midway between the midvein and leaflet margin. Leaflet sections were fixed in $2 \%$ glutaraldehyde and $1 \%$ osmium tetraoxide in $0.085 \mathrm{M}$ cacodylate buffer $(\mathrm{pH} 7.2)$, dehydrated in an ethanol series, critical-point dried, mounted on stubs, and coated with gold-palladium. 'Samples were examined with a Phillips $505 \mathrm{SEM}$ at $15 \mathrm{kV}$.

\section{Results}

The leaflets in Fig. 1 are typical of the differences in sooty mold accumulation observed in the field on 'Stuart' and 'Schley' leaves. Of the cultivars examined, field observations of sooty mold accumulation on the leaf surface indicated that the greatest colonization was on 'Stuart', followed by 'Curtis', and the lowest incidence was on 'Schley' and 'Desirable'. The weighed amount of sooty mold accumulated on leaflets by each cultivar

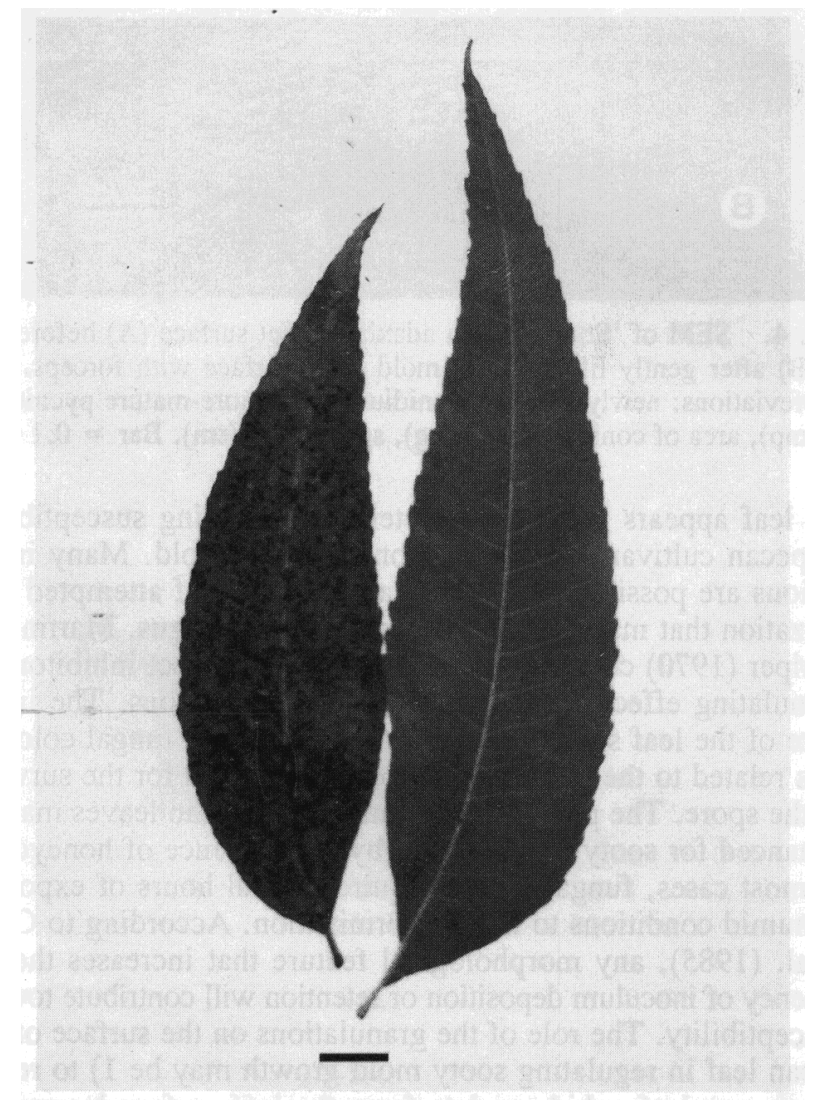

Fig. 1. Intact pecan leaflet from (left) 'Stuart', a cultivar scored as having high levels of sooty mold, and (right) 'Schley', a cultivar scored as having low levels of sooty mold accumulation. Bar $=1$ $\mathrm{cm}$.
(Fig. 2) provided evidence for these field observations. The quantity of sooty mold on 'Stuart' leaflets was significantly greater than from any of the other cultivars examined, and that for 'Curtis' was greater than for either 'Desirable' or 'Schley'. The amount of sooty mold accumulated on the latter was $\approx 50 \%$ less than that on 'Curtis' and $75 \%$ less than on 'Stuart'.

Examination of the adaxial leaf surface features by SEM demonstrates that the characteristics of the surface morphology of washed leaves from cultivars that typically have large amounts of sooty mold are very different from cultivars that usually have smaller amounts of sooty mold (Fig. 3). The leaf surfaces of the cultivars with the greatest accumulation of sooty mold'Stuart' and 'Curtis' (Fig. 3 A and B) - are rougher and contain more numerous granulations than the cultivars that commonly do not accumulate appreciable quantities of sooty mold ['Desirable' and 'Schley' (Fig. $3 \mathrm{C}$ and D)].

Sooty mold grows on 'Stuart' pecan leaves as a flat hyphal plate interrupted with occasional aerial fruiting bodies projecting from the plate (Fig. $4 \mathrm{~A}$ and $\mathrm{B}$ ). The fungus composing the sooty mold growth on the leaves of all the cultivars analyzed in this study belongs to Polychaeton sp. (D. Reynolds, personal communication). The fruiting bodies (pycnidia) of this fungus can be seen in various stages of development in Fig. 4A. The shorter stalks are newly formed and the longer stalks are moremature pycnidia. The swollen area on the pycnidium located in the lower left corner is an area in which conidiogenesis is occurring. On a nearby stalk, the rounded apical region is a spore mass that has been exuded to the top of a pycnidial column. Sections of leaves from 'Stuart' that were heavily colonized with sooty mold (Fig. 4A) were examined after peeling away the sooty mold (Fig. 4B). There is neither any apparent change in the leaf topography nor evidence of physical distortion of the leaf surface by the growth of the sooty mold. Examination from a cross-section perspective of 'Stuart' leaves both before (Fig. 5A) and after (Fig. 5B) removal of the sooty mold does not reveal any obvious damage to the integrity of the leaf surface. The elevation of the adaxial wall in the central regions of each epidermal cell appears to be responsible for creating the granulated leaf topography apparent in Figs. 3A and 4B.

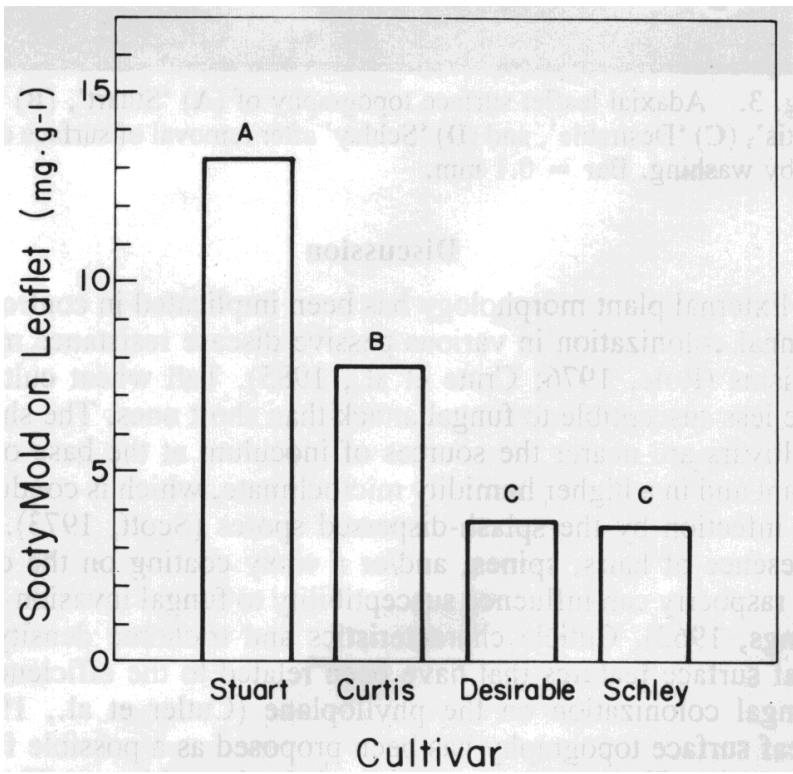

Fig. 2. Quantification of sooty mold accumulation on leaflets from four pecan cultivars. Mean separation by Duncan's multiple range test (Snedecor and Cochran, 1967), $P \leq 0.05$. 

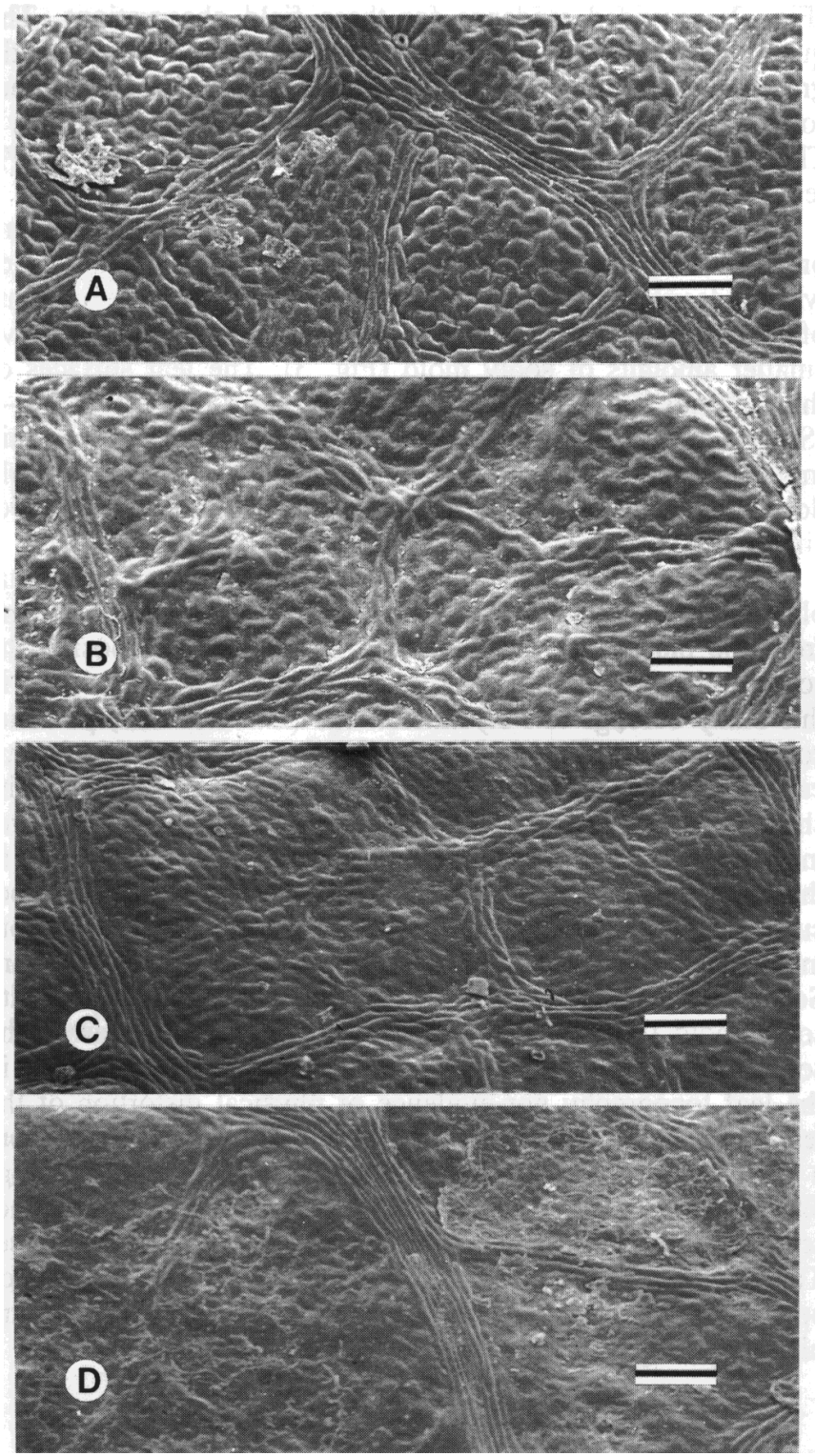

Fig. 3. Adaxial leaflet surface topography of (A) 'Stuart', (B) 'Curtis', (C) 'Desirable', and (D) 'Schley' after removal of surface debris by washing. Bar $=0.1 \mathrm{~mm}$.

\section{Discussion}

External plant morphology has been implicated in controlling fungal colonization in various passive disease resistance mechanisms (Role, 1976; Crute et al., 1985). Tall wheat cultivars are less susceptible to fungal attack than short ones. The shorter cultivars are nearer the sources of inoculum at the base of the plant and in a higher humidity microclimate, which is conducive to infection by the splash-dispersed spores (Scott, 1973). The presence of hairs, spines, and/or a waxy coating on the canes of raspberry can influence susceptibility to fungal invasion (Jennings, 1962). Cuticle characteristics and trichome density are leaf surface features that have been related to the efficiency of fungal colonization on the phylloplane (Cutler et al., 1986). Leaf surface topography has been proposed as a possible factor governing Uromyces appendiculus infection of beans (Hoch et al., 1987).

From the cultivars analyzed in this study, the topography of
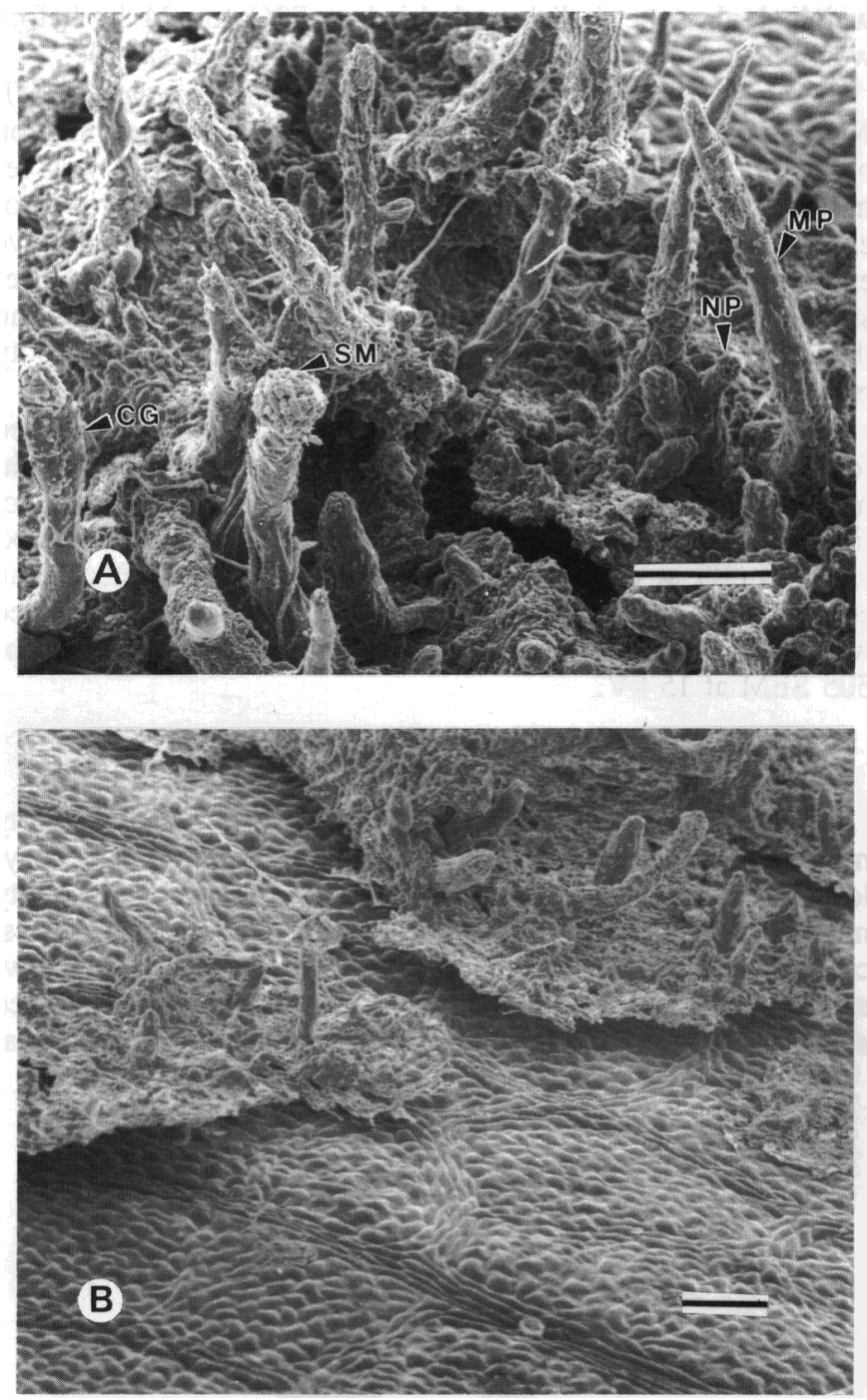

Fig. 4. SEM of 'Stuart' pecan adaxial leaflet surface (A) before and (B) after gently lifting sooty mold from surface with forceps. Abbreviations: newly formed pycnidium (rip), more-mature pycnidium (rep), area of conidiogenesis (cg), spore mass (sin). Bar $=0.1 \mathrm{~mm}$.

the leaf appears to be a characteristic mediating susceptibility of pecan cultivars to colonization by sooty mold, Many interactions are possible during the earliest stages of attempted colonization that may affect the success of the fungus. Martin and Juniper (1970) considered cuticles had little direct inhibitory or stimulating effect on potential growth of microbes. The influence of the leaf surface on the establishment of fungal colonies was related to the physical environment created for the survival of the spore. The physical environment on pecan leaves may be enhanced for sooty mold growth by the presence of honeydew. In most cases, fungal spores require several hours of exposure to humid conditions to induce germination. According to Crute et al. (1985), any morphological feature that increases the efficiency of inoculum deposition or retention will contribute toward susceptibility. The role of the granulations on the surface of the pecan leaf in regulating sooty mold growth maybe 1) to retard the removal of aphid exudate from the leaf surface by run-off and rain, thereby providing a more nutritive medium for fungal growth; 2) to provide a higher humidity site for sporulation in that the crevices created by convolutions may not dry as quickly 

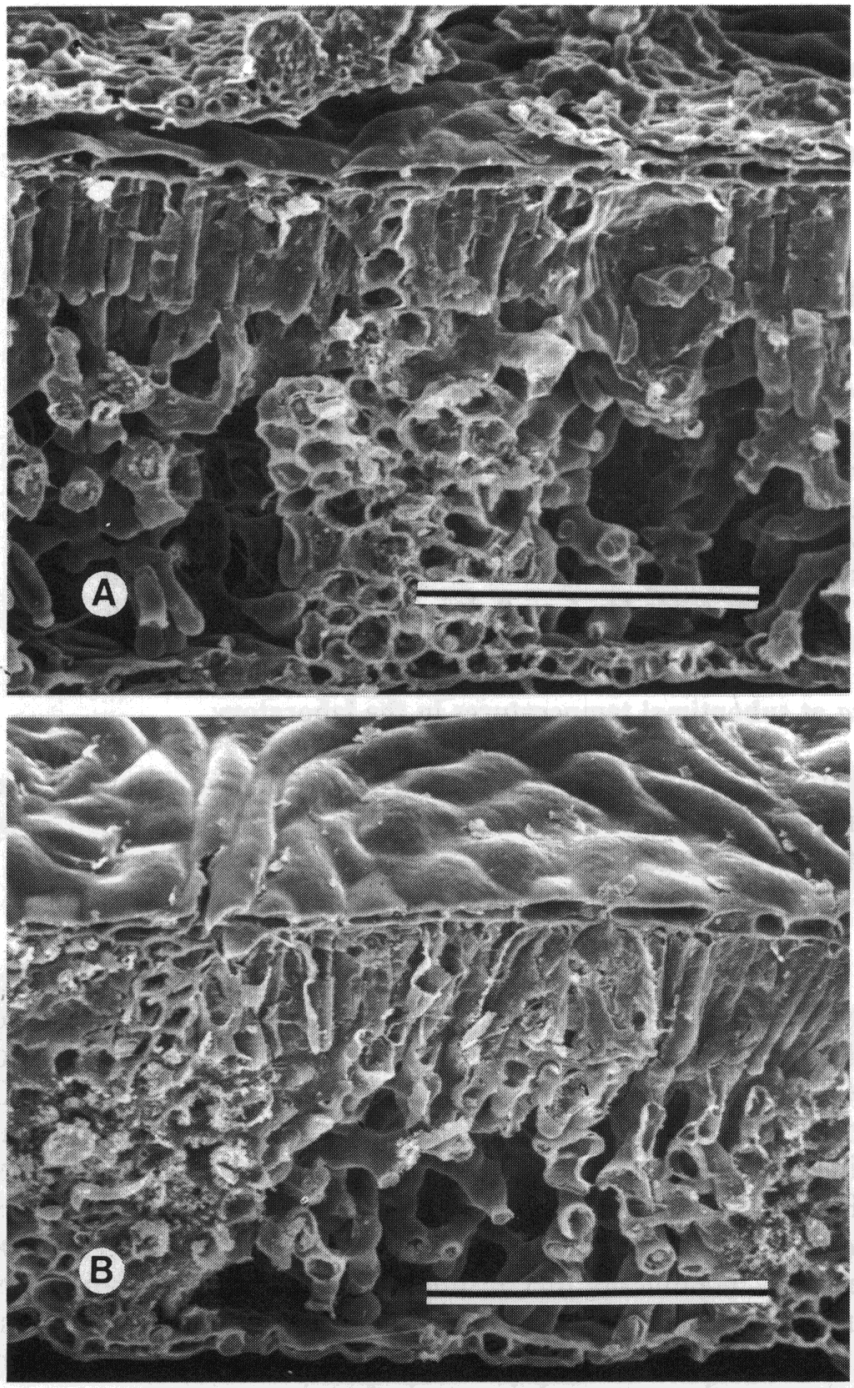

Fig. 5. SEM of 'Stuart' pecan leaflet cross section (A) before and (B) after sooty mold removal. Bar $=0.1 \mathrm{~mm}$.

after rain or dew deposition; and/or 3) to increase the retention of spores on the leaf surface so that the density of the spore inoculum is greater in cultivars such as 'Stuart'. Any one of these functions could contribute to an epidemic development of sooty mold by influencing the conditions created on the host plant. The possibility exists that factors other than leaf surface morphology govern sooty mold accumulation. If so, these factors are expected to be highly correlated with leaf morphology.

Regardless of the plant defense mechanisms involved in the differential growth of sooty mold among pecan cultivars, the quantity of this fungus on 'Stuart' leaves was significantly greater than on any of the other cultivars examined, and that on 'Curtis' was greater than on either 'Schley' or 'Desirable'. A fungicide probably can be developed to control sooty mold. In early and mid-season sprays, the fungicide could be tank-mixed with fungicides targeted for scab, thus minimizing the cost. However, in arid climates, where diseases are not normally a problem, fungicide sprays would have to be targeted specifically for sooty mold. Similarly, in humid climates, specific sprays for sooty mold would have to be applied if accumulation occurs late in the season or after threat of other pecan diseases has passed. In any case, sprays for sooty mold would result in additional production cost.
Leaf surface topography appears to be a suitable marker that potentially could be used in breeding programs to select genotypes with minimum sooty mold susceptibility. Although the accumulation of sooty mold on pecan leaves may involve multidimensional factors at both the biotic and abiotic levels, leaf topography may represent at least one of the factors involved in pest defense strategies among the cultivars of pecan.

\section{Literature Cited}

Crute, I. R., P.J.G.M. De Wit, and M. Wade. 1985. Mechanisms by which genetically controlled resistance and virulence influence host colonization by fungal and bacterial parasites, p. 197-309. In: R.S.S. Fraser (cd.). Mechanisms of resistance to plant diseases. Martinus Nijhoff/Junk, Boston.

Cutler, H. G., R.F. Severson, P.D. Cole, D.M. Jackson, and A.W. Johnson. 1986. Secondary metabolizes from higher plants - their possible role as biological control agents, p. 178-196. In: M.B. Green and P.A. Hedin (eds.). Natural resistance.of plants to pestsRoles of allelochemicals. Amer. Chem. Soc., Washington, D.C.

Hinrichs, H.A. 1962. Pecan industry and some research developments in Oklahoma. Annu. Rpt. Northern Nut Growers Assn. 53:80-85.

Hoch, H. C., R.C. Staples, B. Whitehead, J. Comeau, and E.D. Wolf. 1987. Signaling for growth orientation and cell differentiation by surface topography in Uromyces. Science 235:1659-1662.

Jennings, D.L. 1962. Some evidence on the influence of the morphology of raspberry canes upon their liability to be attacked by certain fungi. Hort. Res. 1:100-111.

Martin, J.T. and B.E. Juniper. 1970. The cuticles of plants. Edward Arnold, London.

Moznette, G. F., C.B. Nickels, W.C. Pierce, T.L. Bissell, J.B. Demaree, J.R. Cole, H.E. Parson, and J.R. Large. 1940. Insects and diseases of the pecan and their control. U.S. Dept. Agr. Farmers' Bul. 1829.

Parbery, I.H. and J.F. Brown. 1986. Sooty moulds and black mildews in extra-tropical rainforests, p. 101-120. In: N.J. Fokkema and J. Van Den Heuvel (eds.). Microbiology of the phyllosphere. Cambridge Univ. Press, New York.

Royle, D.J. 1976. Structural features of resistance to plant diseases, p. 161-193. In: J. Friend and D.R. Threlfall (eds.). Biochemical aspects of plant-parasite relationships. Academic, New York.

Scott, P.R. 1973. Incidence and effects of Septoria nodorum on wheat cultivars. Ann. Applied Biol. 75:321-329.

Snedecor, G.W. and W.G. Cochran. 1967. Statistical methods. Iowa State Univ. Press, Ames.

Sparks, D. 1986. Pecan, p. 323-339. In S.P. Monselise (cd.). CRC handbook of fruit set and development. CRC Press, Boca Raton, Fla.

Sparks, D. and C.E. Brack. 1972. Return bloom and fruit set of pecan from leaf and fruit removal. HortScience 7:131-132.

Tedders. W .L. 1978. Important biological and morphological characteristics of the foliar-feeding aphids of pecan. U.S: Dept Agr. Tech. Bul. 1579.

Tedders, W.L. and J.S. Smith. 1976. Shading effect on pecan by sooty mold growth. J. Econ. Entomol. 69:551-553.

Tedders, W. L., B.W. Wood, and J.W. Snow. 1982. Effects of feeding by Monelliopsis nigropunctata, Monellia caryella, and Melanocallis caryaefoliae on growth of pecan seedlings in the greenhouse. J. Econ. Entomol. 75:287-291.

Thompson, T.E. and I. Yates. 1986. Glandular hairs act as aphid resistance mechanism in pecan. Pecan South 20(6):8-9.

Wood, B. W., W.L. Tedders, and C.C. Reilly. 1988. Sooty mold fungus on pecan foliage suppresses light penetration and net photosynthesis. HortScience 23:851-853.

Worley, R.E. 1979. Fall defoliation date and seasonal carbohydrate concentration of pecan wood tissue. J. Amer. Soc. Hort. Sci. 104:195199. 